\title{
EFEITOS NATURAIS E ANTRÓPICOS NA QUALIDADE DA ÁGUA DA BACIA HIDROGRÁFICA DO RIO APODI/MOSSORÓ
}

Jesyka Macêdo Guedes*(Graduanda em Química na Universidade do Estado do Rio Grande do

$$
\text { Norte - UERN) }
$$

Adriana Valentim Wandernurem (Mestranda do PPGCN da Universidade do Estado do Rio

$$
\text { Grande do Norte - UERN) }
$$

Suely Souza Leal de Castro (Prof. Adjunta do Dq e do PPGCN na Universidade do Estado do

$$
\text { Rio Grande do Norte - UERN) }
$$

Jefferson Bezerra de Medeiros (Graduand0 em Química na Universidade do Estado do Rio

$$
\text { Grande do Norte - UERN) }
$$

Luiz Di Souza (Prof. Adjunto do Dq e do PPGCN na Universidade do Estado do Rio Grande do

$$
\text { Norte - UERN) }
$$

Email: Jesyka.mg@hotmail.com

\section{Resumo:}

Tendo em vista a má distribuição das águas no mundo e o conhecimento da escassez desse recurso na região do nordeste brasileiro, que sofre com secas extremas, aumentou a preocupação em relação aos cuidados com os recursos hídricos e sua qualidade nesta região. Por esse motivo, os órgãos ambientais e de gestão das águas se preocupam em avaliar a presente situação desses reservatórios, pois o controle da poluição está diretamente relacionado com a proteção da saúde, da flora e da fauna, garantia do meio ambiente ecologicamente equilibrado e a melhoria da qualidade de vida. Essa avaliação leva em conta os usos prioritários e as classes de qualidade ambiental exigidos para um determinado corpo de água. Para ter conhecimento de como se encontra a qualidade da água na região do semiárido do Rio Grande do Norte, foram coletadas a princípio amostras de água usando metodologias padrões e as normas vigentes no país e avaliaram-se as condições da sua qualidade na bacia hidrográfica do rio Apodi/Mossoró, região que passa por uma situação de extrema seca nos últimos cinco anos. Os resultados analisados mostraram que: Os valores de Cl, P, Dureza, TOG, $\mathrm{N}_{\mathrm{T}}$ e SDT estão fora dos padrões propostos pela legislação federal (resolução $n^{\circ}$ 357/2005 do CONAMA), que essa não conformidade tem relação direta com a escassez de chuvas na região e a espacialidade dos mananciais, pois a seca já dura 5 anos e a maioria dos reservatórios estão sem água ou com volumes muito baixos.

\section{Palavras-chave:}

Recursos hídricos; poluição; legislação e estiagem. 


\section{1-introdução}

A especulação sobre a qualidade da água tem aumentado em todo o mundo, isso acontece pela escassez desse bem tendo em vista a sua total necessidade. Segundo Miller (2008), a superfície terrestre é formada por aproximadamente $71 \%$ de água. Á primeira vista, o abastecimento de água parece inesgotável, mas se considerarmos que 97\% são águas salgadas (mares, oceanos) não utilizáveis para a agricultura, uso industrial, ou consumo humano, a impressão já muda. Agrava-se ainda mais quando se observa que dos 3\%, de água doces, 2,7\% são formadas por geleira, vapor de água e lençóis existentes em grandes profundidades (mais de $800 \mathrm{~m}$ ), fontes muitas vezes não economicamente viáveis de aproveitamento para o consumo humano atualmente. Em consequência, constata-se que somente $0,3 \%$ do volume total de água do planeta pode ser aproveitado para consumo humano, sendo 0,01\% encontrados em fontes de superfície (rios, lagos, lagoas) e o restante, ou seja, 0,29\%, em fontes subterrâneas (poços e nascentes). A água subterrânea vem sendo acumulada no subsolo há séculos e somente uma fração desprezível é acrescentada anualmente através das chuvas que não cobre ao que é retirada pelo homem. Em compensação, a água dos rios é renovada cerca de 31 vezes, anualmente. A precipitação anual, na terra, é de cerca de $860 \mathrm{~mm}$ e enntre 70 e $75 \%$ dessa precipitação voltam à atmosfera como evapotranspiração, sendo estes $30 \%$ a maior fonte de água útil para uso humano (FUNASA, 1999).

O Brasil possui cerca de $8 \%$ de toda água doce do planeta, porém a região Amazônica com $5 \%$ da população tem $80 \%$ desta água, e as outras regiões, com $95 \%$ da população, tem apenas 20\% (SOUSA, 2000). Nordeste brasileiro a situação é mais crítica, sendo que o mapa dos recursos hídricos traçado pela Agência Nacional de Águas (ANA) comprova que o Nordeste possui a menor disponibilidade hídrica do país, 3\%. Tendo em vista a má distribuição dessa água só nos resta cuidar desse bem tão valioso. Pois, esse elemento é indispensável à sobrevivência de todos os organismos vivos, além disso, é extremamente importante para a manutenção do clima na Terra. (SIQUEIRA; APRILE e MIGUEIS. 2012). Dentre os muitos aspectos apresentados pela região o que mais se destaca é a seca, causada pela escassez de chuvas. No sertão, as chuvas ocorrem entre dezembro e abril, no entanto, em determinados anos isso ocorre que menos frequência, ocasionando um longo período com poucas chuvas, as chamadas secas. Atualmente essa seca dura 5 anos no Nordeste brasileiro, o que tem causado uma série de problemas graves, pois com a escassez de chuvas diminui a quantidade de água potável, a falta de água pode causar a morte de rebanhos e, principalmente, diminuição da qualidade da água causada pela concentração dos poluentes a medida que a água evapora dos reservatórios.A figura 1 ilustra esse fenômeno em todo o Nordeste brasileiro, deixando claro que a pouca quantidade de água que normalmente existe no NE neste momento diminuiu para um quarto, o que representa uma situação extremamente grave.

Figura

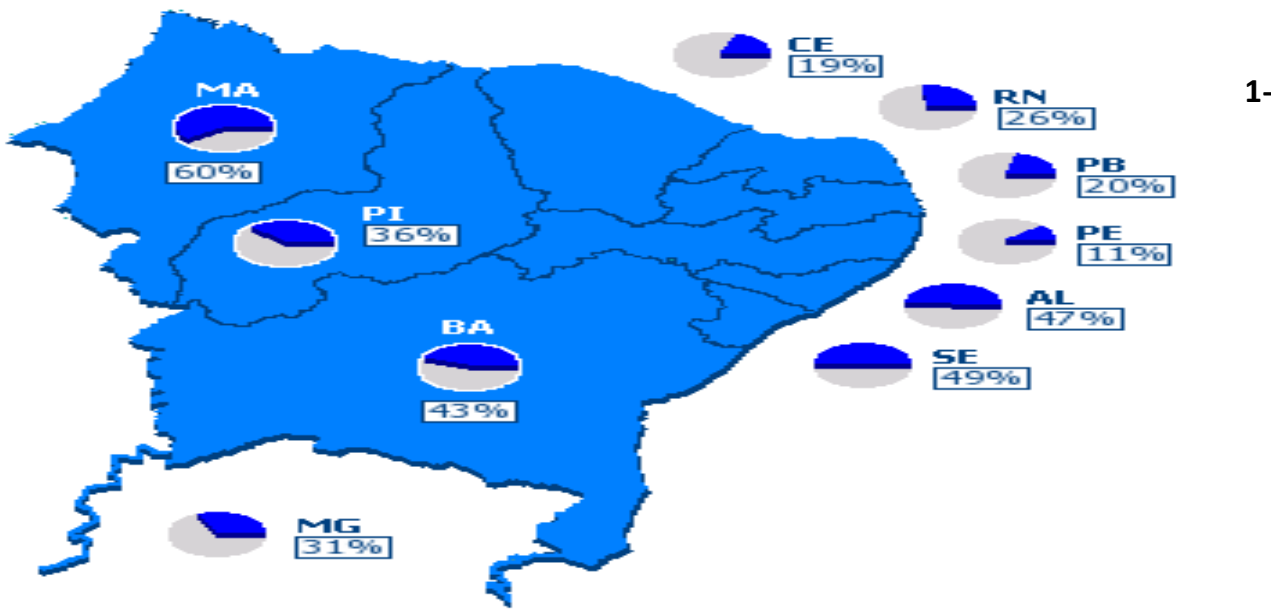

$1-$

Percentual de água disponível nos reservatórios da região NE em julho de 2015. Fonte: DNOCS, 2015. http://www.dnocs.gov.br/ dnocs/php/comunicacao/monitoramento_de_reservatorios.php> Acesso em 28 set. 15. 
A tabela 1 mostra a situação das reservas de água em seis dos grandes reservatórios da região em 2011 e em 2015 e o percentual de água perdido nos últimos 5 anos.

Tabela 1 - Percentual de água nos açudes do RN em 2011 e em 2015.

\begin{tabular}{cccc} 
AÇUDES & \% DE ÁGUA/2011 & \% DE ÁGUA/2015 & $\begin{array}{c}\text { \% PERDIDO } 2011 \\
\mathbf{- 2 0 1 5}\end{array}$ \\
\hline $\begin{array}{c}\text { AÇUDE ITANS } \\
\text { AÇUDE PAU DOS } \\
\text { FERROS }\end{array}$ & 73,88 & 8,63 & 88,32 \\
AÇUDE BONITO \\
II
\end{tabular}

Fonte: DNOCS,2015.

http://www.dnocs.gov.br/ dnocs/php/comunicacao/monitoramento_de_reservatorios.php>

Acesso em 28 set. 15.

Tendo em vista a grave situação que se encontra as reservas de água na região, se faz necessário pelos órgãos ambientais e de gestão das águas conhecer a qualidade das águas, pois o seu controle está diretamente relacionado com a proteção da saúde, da flora e da fauna, com a garantia do meio ambiente ecologicamente equilibrado e com a melhoria da qualidade de vida, levando em conta os usos prioritários e classes de qualidade ambiental exigidos para um determinado corpo de água.

Assim, para conhecer como se encontra a qualidade da água de alguns corpos aquáticos localizados na Bacia hidrográfica do Rio Apodi/Mossoró, foram coletadas amostras de água e avaliou-se as condições da sua qualidade em diversos pontos da bacia hidrográfica, neste momento de extrema seca.

\section{2- Materiais e Métodos}

\section{1- Coletas}

As amostras foram coletadas em alguns pontos estratégicos do percurso do Rio Apodi/ Mossoró e outros pontos da bacia hidrográfica, conforme orientações prescritas na NBR 9897(ABNT, 1987; (Planejamento de amostragem de efluentes líquidos e corpos receptores) e preservadas de acordo com a NBR 9898 (ABNT, 1987; Preservação e técnicas de amostragem de efluentes líquidos e corpos receptores) e analisadas de acordo com as metodologias prescritas no Standard Methods for Examination of Water and Wastewater (APHA, 2005).

Os valores de $\mathrm{pH}$ e temperatura foram medidos em campo utilizando-se medidor multiparamétrico portátil Orion* 5-Star da Thermo Scientific, os demais parâmetros (Cl, Salin., $\mathrm{NO}_{3}, \mathrm{NO}_{2}, \mathrm{NH}_{3}, \mathrm{PO}_{4}$, Alcalin., TOG. Dur. Ca, Mg, Tur. NT e ST) foram quantificados utilizando-se das estruturas dos laboratórios de Biologia I, de Eletroquímica e Química Analítica (LEQA) e do Laboratório de Catálise, Ambiente e Materiais (LACAM), todos pertencentes a Universidade do Estado do Rio Grande do Norte - UERN. Todas as análises 
foram feitas em triplicata e a média aritmética das medidas foi considerada como sendo o resultado das mesmas.

\section{2- Caracterizando a área de estudo}

A bacia hidrográfica do rio Apodi/Mossoró (figura 2) ocupa uma superfície de $14.276 \mathrm{~km}^{2}$, correspondendo à cerca de $26,8 \%$ do território do RN e constitui um dos mais importantes recurso hídrico da região oeste Potiguar. Assim o rio Apodi-Mossoró nasce no município de Luiz Gomes, sendo caracterizado um rio temporário, devido a sua própria estrutura geológica. À medida que o rio se aproxima do município de Governador Dix-sept Rosado observa-se o início de uma bacia sedimentar, caracterizando um ecossistema de caráter permanente em função do represamento das águas pela barragem Santa cruz do Apodi e controle da vazão a jusante por abertura de suas comportas até a região de foz que fica entre os municípios de Grossos e Areia Branca.

Levando-se em consideração fatores geográficos e culturais, o rio Apodi/Mossoró pode ser dividido da seguinte forma: curso superior - compreendendo a área de nascente no município de Luiz Gomes (cabeceira do rio) em uma altitude em torno de 700 metros, se estendendo até a barragem de Santa Cruz; curso médio - iniciando a jusante da represa de Santa Cruz e indo até Mossoró; curso inferior ou região estuarina nos municípios de Mossoró, Areia Branca e Grossos. No geral o curso superior é considerado de caráter temporário, já o curso médio e inferior são considerados de caráter permanentes.

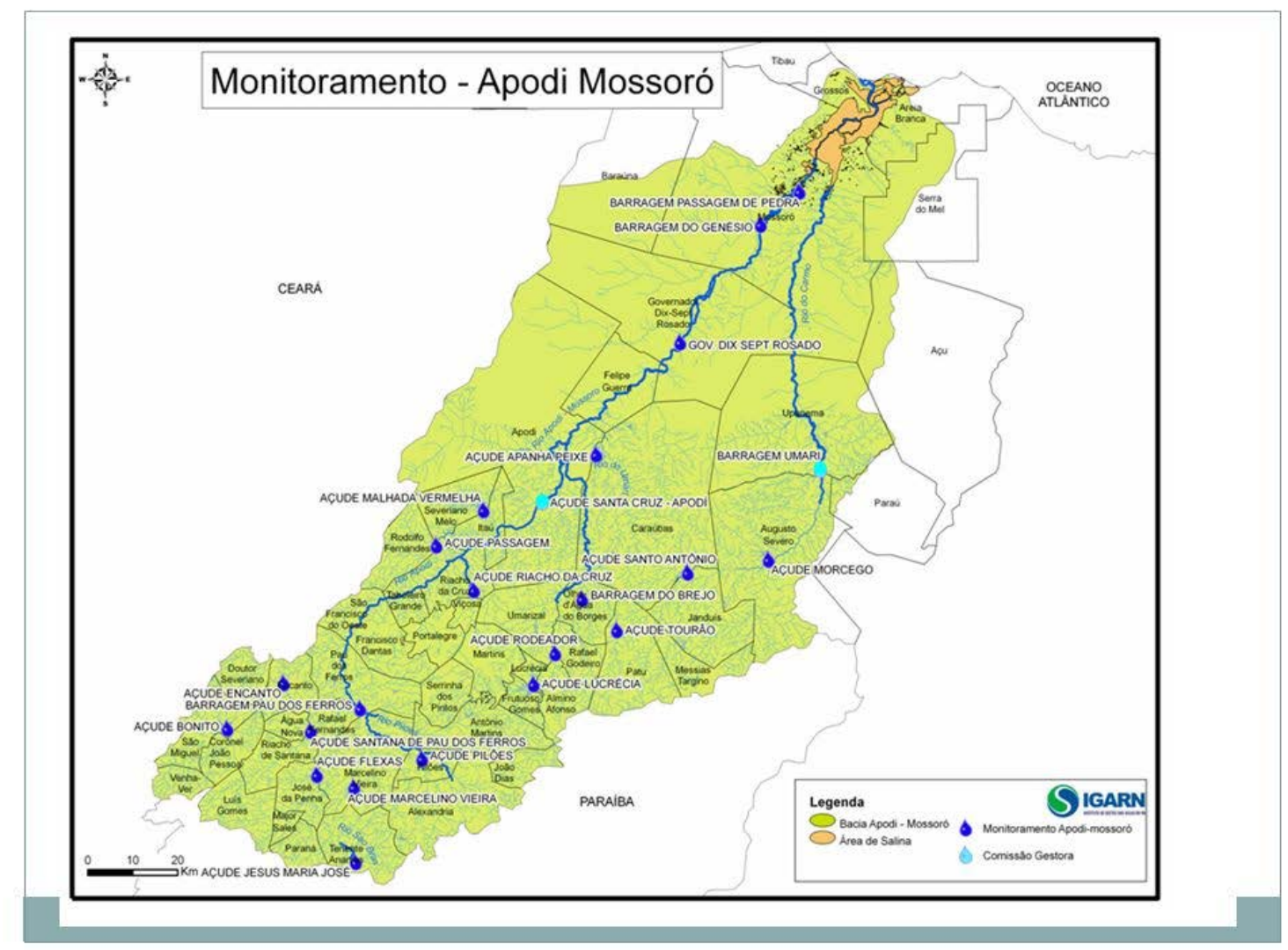

Figura 2: Mapa da região estudada a bacia hidrográfica Apodi/Mossoró.

Fonte: Site da SEMARH, Site: http://www.semarh.rn.gov.br/acessado em setembro de 2015. 


\section{3- Resultados e Discussão}

De acordo com a resolução CONAMA n ${ }^{0} 357 / 2005$, que dispõe sobre a classificação dos corpos de água e diretrizes ambientais para o seu enquadramento, os recursos hídricos superficiais são classificadas em águas doces (salinidade $\leq 0,5 \%$ ), salobras $(0,5 \%<$ salinidade $<30 \%$ ) e salgadas ( $30 \%_{0} \geq$ salinidade). Os valores encontrados nos diferentes parâmetros analisados estão informados na tabela (2) a seguir.

Tabela 2- Resultados dos diversos parâmetros físico-químicos encontrados para as amostras de água analisadas e seus limites no CONAMA 357/2005.

\begin{tabular}{|c|c|c|c|c|c|}
\hline PARAMETROS & $\begin{array}{c}\text { P1 } \\
\text { (PORTO } \\
\text { A. B.) }\end{array}$ & $\begin{array}{c}\text { P2 } \\
\text { (PORTO } \\
\text { GROSSOS) }\end{array}$ & $\begin{array}{c}\text { P3 } \\
\text { (PONTE } \\
\text { BR AB) }\end{array}$ & $\begin{array}{c}\text { P4 } \\
\text { (PASS. } \\
\text { PEDRAS) }\end{array}$ & $\begin{array}{r}\text { CONAMA } \\
357 / 2005\end{array}$ \\
\hline pH & 7 & 8 & 8 & 8 & 6.0 a 9.0 \\
\hline Temperatura & 27 & 27 & & 28 & \\
\hline Amônia/ ppm & 0,132 & 0,119 & 0,084 & 1,626 & $\begin{array}{c}5,6 \text { ppm } \\
\mathrm{N}, \text { para } 7,5 \\
<\text { pH } \leq 8,0\end{array}$ \\
\hline Cloreto/ ppm & 113.400 & 14.000 & 8.400 & 616 & $\underset{\mathrm{Cl}}{250 \mathrm{ppm}}$ \\
\hline Alcalinidade/ ppm & 64 & 70 & 112 & 134 & $\begin{array}{c}25 \text { e } 100 \\
\mathrm{ppm}\end{array}$ \\
\hline Salinidade/ ppm & 186.883 & 23.072 & 13.843 & 1.015 & \\
\hline Fósforo/ ppm & 0,194 & 0,118 & 0,144 & 0,158 & $\begin{array}{c}0,075 \mathrm{ppm} \\
\text { P }\end{array}$ \\
\hline Dureza/ ppm & 7617,35 & 7212,70 & 7688,16 & 404,64 & \\
\hline $\mathrm{Ca} / \mathrm{ppm}$ & 93,78 & 218,03 & 70,54 & 13,63 & \\
\hline $\mathrm{Mg} / \mathrm{ppm}$ & 309.16 & 214.47 & 326,66 & 11,18 & \\
\hline Tog & 119 & 19 & 15 & 16 & 0 \\
\hline Nitrito/ ppm & 0,0035 & 0,0063 & 0,0158 & 0,0187 & $1,0 \mathrm{ppm} \mathrm{N}$ \\
\hline N.total/ ppm & 5,295 & 5,587 & 14,825 & 7,483 & \\
\hline Nitrato/ppm & 3,635 & 4,184 & 6,906 & 5,524 & $\begin{array}{c}10,0 \mathrm{ppm} \\
\mathrm{N}\end{array}$ \\
\hline St/ppm & 64.424 & 61.930 & 31.772 & 1.640 & $500 \mathrm{ppm}$ \\
\hline
\end{tabular}

Fonte: autoria própria

De acordo com esta classificação os resultados indicam que os pontos 1, 2 e 3 são águas salgadas, os pontos 4, 5 e 6 são águas salobras e os pontos 7, 8 e 9 são de águas doces. Porém os pontos 5 e 6 estavam completamente eutrofizados e não ofereceram condições de coleta de água em função do mau cheiro e do aspecto da água. Resultados coerentes com o fato dos pontos salgados se encontrarem na região estuarina do rio, onde ocorre a mistura ou influência dos mares e com as quantidades de água encontradas no rio Apodi/Mossoró e nos reservatórios lagoa do Apodi e Barragem Santa cruz, sendo que a lagoa se apresenta quase seca $(25 \mathrm{~cm}$ de água nos pontos mais fundos e cerca de $90 \%$ da sua área seca) e os pontos a jusante da barragem são influenciados pela diminuição do volume liberado pela barragem.

Em relação aos resultados da tabela 2, os valores de temperatura se encontram dentro das normas permitidas. Segundo a Companhia Ambiental do Estado de São Paulo, a temperatura é parte do regime climático normal e corpos de água naturais apresentam variações sazonais e diurnas. A temperatura superficial é influenciada por fatores tais como latitude, altitude, estação do ano, período do dia, taxa de fluxo e profundidade. A elevação da temperatura em um corpo d'água, geralmente, é provocada por despejos industriais e usinas termoelétricas. Os valores de T giraram em torno de 27 a $30^{\circ} \mathrm{C}$, indicando que as águas do Rio do Apodi/Mossoró não recebem descargas de águas em elevadas temperaturas. 
Tabela 2- Resultados dos diversos parâmetros físico-químicos encontrados para as amostras de água analisadas e seus limites no CONAMA 357/2005. (Continuação).

\begin{tabular}{|c|c|c|c|c|c|c|}
\hline PARAMETROS & $\begin{array}{c}\text { P7 } \\
\text { (BAR. } \\
\text { GENESIO) }\end{array}$ & $\begin{array}{c}\text { P8 } \\
\text { (LAGOA } \\
\text { APODI) }\end{array}$ & $\begin{array}{c}\text { P9 } \\
\text { (BAR. S. } \\
\text { CRUZ) }\end{array}$ & $\begin{array}{c}\text { P10 } \\
\text { (ENT.G. } \\
\text { D.R.) }\end{array}$ & $\begin{array}{c}\text { P11 } \\
\text { (SAIDA } \\
\text { G.D.R.) }\end{array}$ & $\begin{array}{c}\text { CONAMA } \\
357 / 2005\end{array}$ \\
\hline pH & 8 & 8 & 8 & 8 & 8 & 6.0 a 9.0 \\
\hline Temperatura & 28 & 28 & 29 & 30 & 30 & \\
\hline Amônia/ ppm & 0,128 & 0,0685 & 0,0454 & 0,0840 & 0,0741 & $\begin{array}{c}5,6 \mathrm{ppm} N \\
\text { para } 7,5< \\
\text { pH } \leq 8,0\end{array}$ \\
\hline Cloreto/ ppm & 686 & 2.100 & 56 & 105 & 126 & $250 \mathrm{ppm} \mathrm{Cl}$ \\
\hline $\begin{array}{c}\text { Alcalinidade/ } \\
\text { ppm }\end{array}$ & 106 & 66 & so & 115 & 90 & $\begin{array}{c}25 \text { e } 100 \\
\text { ppm }\end{array}$ \\
\hline Salinidade/ ppm & 1.131 & 3.460 & 93 & 173 & 208 & \\
\hline Fósforo/ ppm & 0,105 & 0,138 & 0,076 & 0,068 & 0,071 & 0,075 ppm $P$ \\
\hline Dureza/ ppm & 664.6 & 161.86 & 131.51 & 343.94 & 303.47 & \\
\hline $\mathrm{Ca} / \mathrm{ppm}$ & 26,45 & 4,01 & 4,01 & 18,562 & 13,627 & \\
\hline $\mathrm{Mg} / \mathrm{ppm}$ & 48,13 & 5,35 & 3.89 & 11.235 & 6,32 & \\
\hline Tog & 6,7 & 1 & 6,3 & 17 & 10,7 & 0 \\
\hline Nitrite/ ppm & 0,0323 & 0,0113 & 0,0090 & 0,0257 & 0,0108 & $1,0 \mathrm{ppm} \mathrm{N}$ \\
\hline N.total ppm & 7,404 & 8,749 & 4,478 & 4,654 & 7,336 & $2,18 \mathrm{ppm}$ \\
\hline Nitrato/ppm & 1,982 & 0,824 & 3.492 & 4,252 & 6,428 & $10.0 \mathrm{ppm} \mathrm{N}$ \\
\hline St/ppm & 1.978 & 260 & 318 & 626 & 692 & $500 \mathrm{ppm}$ \\
\hline
\end{tabular}

Fonte: autoria própria

Com relação ao pH para rios classe II, a resolução CONAMA nº 357/2005 estabelece uma faixa de pH entre 6.0 e 9.0, significando que nos pontos estudados, os resultados estão de acordo com a resolução.

A Alcalinidade, por sua vez, apresenta-se quando o pH da água está acima de 7. Os principais constituintes que determinam este parâmetro são os íons: bicarbonato $\left(\mathrm{HCO}^{-3}\right)$, carbonato $\left(\mathrm{CO}_{3}{ }^{2-}\right)$; e hidróxidos $\left(\mathrm{OH}^{-}\right)$. A alcalinidade em alguns pontos analisados manteve-se em níveis considerados aceitáveis, sendo estes, valores situados entre 25 e 100 mg L-1 (BOYD, 1990), porém os pontos P3, P4 e P7 ligeiramente acima dos ideais, provavelmente, por causa da pouca vazão existente nestes locais estar sendo muito influenciada pela descarga de efluentes domésticos que aumentam a alcalinidade.

Os teores de amônia encontrados estão abaixo dos valores estabelecidos pela resolução CONAMA $\mathrm{n}^{\circ} 357 / 2005$ que é de $5,6 \mathrm{mg} / \mathrm{L}$ de $\mathrm{N}$, para 7,5 $<\mathrm{pH} \leq 8,0$. A amônia pode estar presente naturalmente em águas superficiais ou subterrâneas, sendo que usualmente sua concentração é bastante baixa devido à sua fácil adsorção por partículas do solo ou à oxidação a nitrito e nitrato. Com relação aos valores de nitrito todos os casos também estão abaixo do valor máximo permitido, isso acontece por o nitrito ser um composto nitrogenado, bastante instável e intermediário do processo de oxidação de íons amônio a íons nitrato (MARTINS, MOURA e SOUZA, 2010). A resolução do CONAMA, não estabelece valores limites para concentração de NT em águas doces classe III. Ela faz apenas inferência para águas doces classe I e II. No artigo 10 , $\S 3^{\circ}$ diz; quando o nitrogênio for fator limitante para eutrofização, nas condições estabelecidas pelo órgão ambiental competente, o valor do nitrogênio total (após oxidação) não deverá ultrapassar 2,18 $\mathrm{mg} \mathrm{L}^{-1}$ para ambientes lóticos, na vazão de referência, tendo em vista essa referência os valores encontrados para NT em todos os casos encontram-se bem acima do valor, isso pode acontecer pela escassez de água dos últimos 5 anos no local das coletas.

Os resultados de fósforo total, ficaram acima do limite máximo permitido $(\leq 0,05 \mathrm{mg} / \mathrm{L})$ estabelecido pela resolução CONAMA nº 357/2005. A presença de fósforo em águas naturais está associada, principalmente, à descarga de esgotos sanitários (matéria orgânica fecal e 
surfactantes) e aos resíduos de agricultura. O principal problema desencadeado por elevadas concentrações de fósforo em um manancial d'água, está relacionado ao processo de eutrofização, isso porque o fósforo, assim como o nitrogênio, constitui um nutriente essencial para os processos biológicos (SILVA \& SOUZA, 2013).

Com base nos resultados obtidos constatou-se que os resultados de sólidos totais estão na grande maioria a cima dos valores desejáveis estabelecidos pela resolução CONAMA, como mostra no gráfico (1) que definiu o valor máximo de $500 \mathrm{mg} / \mathrm{L}$ de sólidos para águas doces classe III. Em um manancial, sólidos totais correspondem a toda matéria que permanece como resíduo após evaporação de uma amostra de água à temperatura de 103 a $105^{\circ} \mathrm{C}$. A presença de elevados valores de sólidos em um recurso hídrico pode causar efeitos nocivos na vida aquática. Eles podem sedimentar no leito dos rios destruindo organismos que servem de alimentos, prejudicar a desova de peixes, reter bactérias e resíduos orgânicos no fundo do rio, levando desta forma ao processo de decomposição anaeróbia.

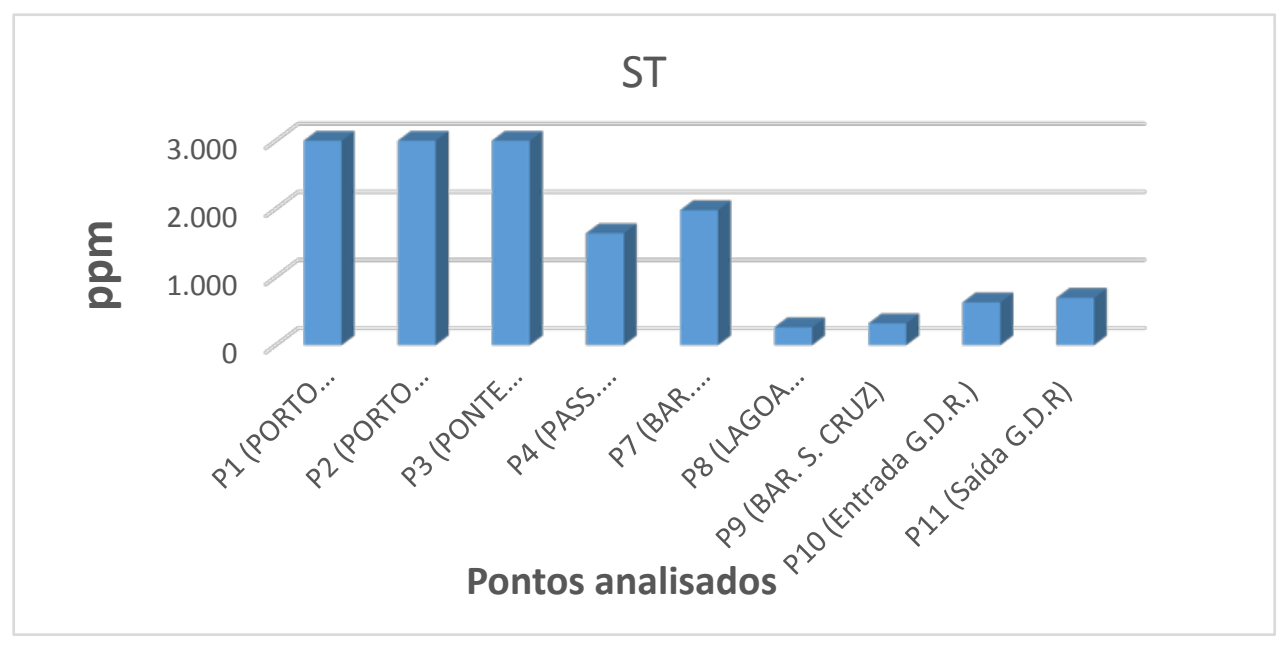

Gráfico 1- Concentração de sólidos totais nos locais analisados em ppm.

O cloreto nos corpos d'água provém geralmente da dissolução de minerais ou da intrusão de águas do mar, podendo também, advir de esgotos domésticos (excreção pela urina) ou industriais (CETESB, 2009). Como padrão de qualidade d'água a resolução CONAMA estabelece o valor máximo de $250 \mathrm{mg} / \mathrm{L}$ de cloreto em águas doce da classe III. Com base nos resultados de cloreto, observa-se os valores ultrapassam, consideravelmente, os valores estabelecidos na resolução, exceto os valores dos pontos 7, 8 e 9. Nos Pontos 1 ,2 e 3 este resultado era esperado em função da região estuarina influir na quantidade de cloreto e a quantidade de cloreto na água do mar da região ser alta, razão pela qual esta região é grande produtora de sal de cozinha $(\mathrm{NaCl})$.

Altos teores de sais minerais, particularmente sulfato e cloreto, estão associados à tendência de corrosão em sistemas de distribuição, além de conferir sabor às águas (CETESB, 2009; BASTOS, 2007).

Para a Dureza e para os íons cálcio $\left(\mathrm{Ca}^{2+}\right)$ e magnésio $\left(\mathrm{Mg}^{2+}\right)$ não foram estabelecidos valores limites de qualidade da água, uma vez que dependendo do solo e da região onde está inserido o recurso hídrico, suas concentrações podem ser elevadas naturalmente. Esses íons são importantes quando associado à dureza total da água. Por definição a dureza total consiste da soma dos íons cálcio e magnésio na água. A portaria nº 518/2004 da ANVISA estabelece 500 $\mathrm{mg} / \mathrm{L}$ para águas de consumo humano. Em comparação com esta portaria, percebe-se que nos pontos P1, P2, P3 e P5, localizados no estuário, os valores de dureza ultrapassam os limites permitidos pela ANVISA, como mostra o gráfico (2). 


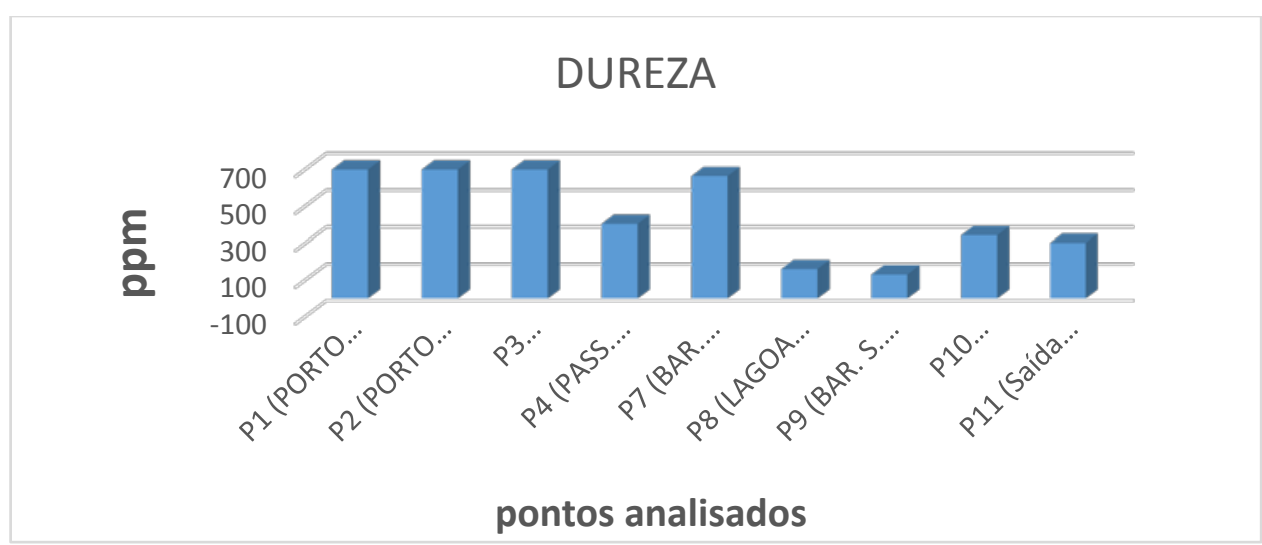

Gráfico 2- Dureza das amostras em função dos locais analisados em ppm.

Em relação aos valores encontrados de óleo e graxa nas amostras analisadas, todos apresentam concentrações de óleo e graxas altos se comparados com a legislação que prevê ausência deste poluente em mananciais. De acordo com os valores encontrados os pontos com os valores mais elevados foram os pontos P1 e P2, isso se deve as atividades marítimas do local, pois se trata de portos marítimos. Onde ocorre a lavagem de embarcações e o descarte de óleos de forma inadequada. Quando o teor de óleos e graxas é reduzido, não traz inibição aos tratamentos biológicos, por este motivo, a legislação federal (resolução $n^{\circ}$ 357/2005 do CONAMA), estabelece os limites máximos de descarte de óleos em efluentes como 50mg/L para óleos de origem vegetal e 20mg/L para óleos minerais, valores superados no ponto 1 . (KATO et al., 1983).

Os valores encontrados $n$ trabalho foram superiores aos encontrados por Castro et al.(2012) estudando os mesmos pontos deste trabalho em 2010, 2011 e 2012 e foram, também, maiores que os de Lemos, Neto e Dias (2010), estudando o ponto P8 (lagoa do Apodi no mesmo ano, o que indica uma forte influência da seca na qualidade da água.

\section{4- Conclusões}

De acordo com os resultados se constatou que devido ao período de extrema seca enfrentado pela região onde se encontra o Rio Apodi/Mossoró, muitos parâmetros como ST, Cl, Salinidade, $\mathrm{Ca}, \mathrm{Mg}$ e Dureza se encontram muito elevados. Isso se deve a escassez de água no local, já que com ausência de chuvas e elevadas temperaturas as águas do rio evaporam com mais rapidez e as impurezas contidas na mesma se concentram na pouca quantidade de água que resta nos mananciais. Todos os valores de fósforo, Nt e Tog e a maioria dos valores de cloreto, Sólidos totais e Dureza se encontram acima do limite permitido na legislação. De forma geral pode-se dizer que os valores encontrados tendem a aumentar no período de seca e que as condições locais influenciam na qualidade da água. Assim os resultados indicam que as águas analisadas estão muito poluídas e não são convenientes para diversos usos como dessedentação humana, irrigação, e conservação da flora e fauna do entorno do rio Apodi/Mossoró.

\section{EFFECTS NATURAL AND ANTHROPOGENIC THE QUALITY OF THE RIVER BASIN WATER APODI RIO / MOSSORÓ}

\section{Abstract}

In view of the poor distribution of water in the world and the knowledge of the scarcity of this resource in the Brazilian northeastern region, which suffers from severe droughts, increased concern about the care of water resources and their quality in this region. For this reason, environmental and water management agencies are concerned to assess the present situation of these reservoirs, as pollution control is directly related to the protection of health, flora and 
fauna, the ecologically balanced environment assurance and improved quality of life. This assessment takes into account the priority uses and environmental quality classes required for a given body of water. To have knowledge of how to find the water quality in northeast Brazil, were collected the first samples of water using methodologies standards and codes of the country and evaluated the conditions of its quality in the catchment area of the river Apodi / Mossoró region passing by an extreme drought in the past five years. The analyzed results showed that: the Cl values, P, Toughness, TOG, NT and SDT are out of the standards proposed by the federal legislation (Resolution No 20 of CONAMA) that this non-compliance is directly related to the lack of rains in the region and the spatiality of water sources, because the drought has lasted five years and most reservoirs are without water or with very low volumes.

Keywords:

Water resources, pollution, legislation and drought.

Agradecimentos- A Universidade do Estado do Rio Grande do Norte (UERN) e aos laboratórios de Biologia I, de Eletroquímica e Química Analítica (LEQA) e do Laboratório de Catálise, Ambiente e Materiais (LACAM).

\section{5- Referências}

APHA/AWWA/WEF. 2005. Standard methods for examination of water and wastewater. American Public Health Association, American Water Works Association and Water Environment Federation. 21st ed., Washington, USA. 4358 pp.

Associação Brasileira de Normas Técnicas. ABNT. Preservação e técnicas de amostragem de efluentes líquidos e corpos receptores, 1987.

BASTOS, Ivan César de Oliveira. Avaliação do índice da qualidade da água no Ribeirão Capim, Médio Rio Doce - Governador Valadares, MG. 2007. 110 f. Dissertação (Mestrado em Engenharia Ambiental) - Instituto de Ciências Exatas e Biológicas, Universidade Federal de Ouro Preto, Governador Valadares, 2007.

BOYD, C. E. Water quality in ponds for aquaculture. Alabama: Ed. Birmingham Publishing Co, 1990.

BRASIL. Agência Nacional de Águas. Panorama da qualidade das águas superficiais do Brasil: 2012. Agência Nacional de Águas - Brasília: ANA, 2012. 264 p.

Castro, Suely Souza Leal ; SOUZA, Luiz Di ; Silva, Larissa Matilde. Monitoramento espaço temporal da qualidade das águas da bacia hidrográfica do rio Apodi/Mossoró - RN. Química no Brasil. 2012.

CASTRO, Suely Souza Leal de; SOUZA, Luiz Di; DANTAS, I. M. ; SILVA, G. H. G. ;CASTRO, R. S.. Sustainable Use of Water in Tropics and Subtropics: The Case of Apodi/Mossoró River Basin in the Brazilian Semi-Arid. Em: Carolina Bilibio; Oliver Hensel; Jeferson Francisco Selbach. (Org.). Sustainable Water Management in the Tropics and Subtropics - and Case studies in Brasil. 1ed.jaguarão.: Fundação Universidade Federal do Pampa, Unikassel, PGCult-UFMA. 2012.v. 3, p. 537-561.

CETESB. Companhia ambiental do Estado de São Paulo. Relatório de qualidade das águas interiores do Estado de Soa Paulo. São Paulo, CETESB, 2010. 251p.

CETESB.Companhia ambiental do Estado de São Paulo. Relatório da qualidade das águas interiores no estado de São Paulo, CETESB, 2009. 43p. 
Departamento Nacional de Obras Contra as Secas. DNOCS. Disponível em: $<$ http://www.dnocs.gov.br/ dnocs/php/comunicacao/monitoramento_de_reservatorios.php> Acesso em 28 set. 15.

FREITAS, Eduardo De. "A Seca no Nordeste"; Brasil Escola. Disponível em $<$ http://www.brasilescola.com/brasil/a-seca-no-nordeste.htm>. Acesso em 27 de agosto de 2015.

Fundação Nacional de saúde. FUNASA. Relatório final de Impactos na Saúde e no Sistema Único de Saúde Decorrentes de Agravos Relacionados a um Saneamento Ambiental Inadequado. Ano 1999. pág. 245.

Instituto de desenvolvimento sustentável. IDEMA. Disponível em:< http://www.idema.rn.gov.br/> Acesso em: 29 Ago. 2015.

KATO, Mario Takayki. “Óleos e Graxas”. Curso Qualidade da Água, do Ar e do Solo. Escola de Engenharia Mauá, 1983.

LEMOS, Marcírio de; NETO, Miguel Ferreira; DIAS, Nildo da Silva. Sazonalidade e variabilidade espacial da qualidade da água na Lagoa do Apodi, RN. Revista Brasileira de Engenharia Agrícola e Ambiental, v. 14, ano 2010. p. 155-164.

MARTINS, Daniel Freitas Freire; MOURA, Maria de Fátima Vitória; SOUZA, Luiz Di.

Determinação de nitrito em água: Tratamento quimiométrico utilizando um planejamento fatorial $2^{3}$.

MILLER, Global Travel. Ciência Ambiental. São Paulo: Cengage Learning, 2008.

Ministério do Meio Ambiente. Conselho Nacional do Meio Ambiente. Resolução no ${ }^{\circ}$ 357, de 2005. CONAMA: resoluções e outros atos. Brasília, DF, 17 mar. 2005. Disponível em: < http://www.mma.gov.br/port/conama/legiabre.cfm?codlegi=459 > Acesso em: 27 Ago. 2015.

OLIVEIRA, T. M. B. F ; MORAIS, P. R. F. ; CASTRO, Suely Souza Leal ; SOUZA, Luiz Di. Impact study of untreated domestic effluents discharge in the rivers through WQI: a real case in the Apodi/Mossoró basin. Química no Brasil. v. 5, ano 2011. p. 23-31.

SILVA A. G.; SOUZA L. D. Efeitos Antropicos e Sazonais na qualidade da água do rio do Carmo. Revista HOLOS, v. 5, p. 131. 2013.

SIQUEIRA, Gilmar W.; APRILE, Fabio; MIGUEIS, Antônio Miguel. Diagnóstico da qualidade da água do rio Parauapebas (Pará - Brasil). Acta Amaz. [online]. 2012, vol.42, n.3, pp. 413-422. ISSN 0044-5967.

SEMARH- Secretaria de meio ambiente e recursos hídricos do RN. Disponível em: http://www.semarh.rn.gov.br/

SOUSA, Teresinha Gomes Sales. ÁGUA POTÁvel GARANTIA DE QUALIDADE DE VIDA, Anais de evento de Educação Ambiental da Universidade Federal do Piauí. Ano 2002, pág. 16.

SOUZA, L.D.; CASTRO, S. S. L., MARTINS, D. F. F.; OLIVEIRA, T. M. B. F.; BATISTA, R.S. Qualidade físico-química das águas da bacia do Rio Apodi/Mossoró. Química no Brasil, v.2, p.61 - 74, 2007. 